\title{
HIGH-RESOLUTION MELTING CURVE (HRM) ANALYSIS IN GENOTYPIC DISCRIMINATION OF CRYPTOSPORIDIUM ISOLATES FROM STOOL OF EGYPTIAN CHILDREN
}

\section{By}

MARWA M. I. GHALLAB ${ }^{1,2}$, MONA M. KHATER ${ }^{1^{*}}$, KEVIN M. TYLER ${ }^{3}$, MAHA BOUZID ${ }^{3}$, AZZA KAMAL ABD ELMEGIED ${ }^{4}$ and AYMAN A. EL-BADRY ${ }^{1,5}$

Department of Medical Parasitology ${ }^{1}$, Kasr Al-Ainy Faculty of Medicine, Cairo University, Department of Medical Parasitology ${ }^{2}$, Faculty of Medicine,

Kafr El- Sheikh University, Egypt, Biomedical Research Centre 3 , School of Medicine,

Health Policy and Practice, University of East Anglia, UK, Department of

Pediatrics ${ }^{4}$, Kasr Al-Ainy Faculty of Medicine, Cairo University, Egypt, and

Department of Microbiology-Medical Parasitology Section ${ }^{5}$, College of Medicine,

Imam Abdulrahman Bin Fasial University, Dammam, Saudi Arabia

( ${ }^{\star}$ Correspondence: mona.m.khater@kasralainy.edu.eg Mobil: (+2) 01223949372)

\section{Abstract}

Cryptosporidiosis is a recognized child infectious killer and the second cause of diarrheal disease and death in infants. Assessing Cryptosporidium spp. genetic diversity is a real goal to elucidate its transmission dynamics and to design preventive measures in absence of effective treatment. Cryptosporidium isolates in stool of Egyptian children were detected using Acid Fast (AF) staining, copro-nPCR/RFLP assay and real time PCR high-resolution melting (HRM) curve analysis assay. Stool samples were collected from 335 children complaining of diarrhea and other GIT symptoms, attending the outpatient clinic of Abu El Reesh hospital, Kasr Al-Ainy School of Medicine, Cairo University. Two genotypes $C$. hominis and $C$. parvum were identified in 43 isolates from Egyptian children by copro-nPCR targeting COWP gene and HRM assay. Real time PCR HRM curve analysis, a closed-tube genotyping method, targeting ITS-2 gene confirmed the results of copro-nPCR/RFLP. It is simple, rapid, has more sample throughput, analysis capacities and data storage with less carry-over contamination and cost.

\section{Introduction}

Cryptosporidium spp. is a protozoan parasite, descried by WHO as one of kid killers and the second cause for diarrheal illnesses and death in newborns after Rotavirus (Kotloff et al, 2013). Cryptosporidium possesses 24 valid species and more than 44 genotypes infecting many vertebrates, including humans and animals, which differ significantly in their molecular signatures (Cama et al, 2008). Thirteen intestinal and gastric Cryptosporidium species infect immuno-competent and immuno-compromised humans have been reported until now (C. parvum, $C$. hominis, C. meleagridis, $C$. felis, $C$. canis, $C$. suis, C. muris, C. andersoni, C. fayeri, $C$. cuniculus, C. ubiquitum and C. viatorum) (Fayer et al, 2010; Elwin et al, 2012).

Genetic variation among Cryptosporidium isolates was reported and seems to be central to the control of this disease and to the understanding of the intricacies of its epide- miology (Pangasa et al, 2009). Though morphologically similar oocysts exist, it was difficult to accurately differentiate the Cryptosporidium species and genotypes by light microscopy and immunoassays that require using molecular methodologies for a precise diagnosis, and detection of parasitic species which reflects on primary \& secondary prevention strategies (Jothikumar et al, 2008).

Analyzing selected genetic loci by PCRbased techniques or direct DNA sequencing has high sensitivity, which allows for the specific amplification of target genetic loci from small amounts of parasite DNA. PCR was integrated into different genotyping techniques, such as restriction fragment length polymorphism analysis (RFLP), random amplification method and methods detecting conformational polymorphisms or sequencing (Pangasa et al, 2009). Because of the increased interest in genetic analysis of pathogen, there was an extensive spotlight on 
mutation scanning methods, which depend up on melting characteristics of amplicons. PCR-based melting-curve and high-resolution melting-curve (HRM) analyses significantly diminish the time, required for testing, and accomplish high mutation detection rates for small amplicons (Montgomery et al, 2007).

The current study aimed to determine the prevalence of Cryptosporidium spp. among a cohort of Egyptian children using copro AF stain, copro n-PCR/RFLP targeting the COWP gene and evaluating real time PCRcoupled HRM-curve analysis, targeting ITS2 as the genetic marker, for detection of the predominant species of Cryptosporidium sp. infecting humans, and discuss the implications of this molecular-diagnostic approach.

\section{Material and Methods}

Study plan: A cross sectional prospective study was designed including 335 stool samples collected from diarrheic children. Samples were collected from cases attending the outpatient GIT clinic at Cairo University Pediatric Hospital from July $1^{\text {st, }} 2014$ to January $1^{\text {st }} 2016$.

Sample collection and processing: A single fecal sample was taken from each child. Part of each stool specimen was preserved in formalin saline fixative for parasitological coproscopic examination and AF staining and other part was stored at $20^{\circ} \mathrm{C}$ for molecular assays. Coproscopy was carried out in the Diagnostic and Research Unit of Parasitic Diseases (DRUP), copronPCR/RFLP assay was performed in Lab of Molecular Medical Parasitology (LMMP), Department of Medical Parasitology, Faculty of Medicine, Cairo University, Egypt and real-time PCR assay was done at Biotechnology unit of the faculty of Veterinary, Kafr El-Sheikh University, Egypt.

Parasitological coproscopy and AF stain: Fecal samples were examined directly by wet mount and after concentration using a modified Ritchie's biphasic method (Garcia, 2007), and then were permanently stained using cold Kinyoun's AF stain (Biostain
Ready Reagents Ltd Manchester, England) to detect Cryptosporidium sp. copro-oocyst.

Extraction of the genomic DNA: Genomic DNA was extracted utilizing Favor Prep stool DNA isolation Mini Kit (Favorgen Biotech corporation ping-Tung 908, Taiwan, Cat. No. FASTI001) with modification in the prolongation of incubation after $56^{\circ} \mathrm{C}$ at 10 minutes to $95^{\circ} \mathrm{C}$ for one hour after thermal shock (cycling of deep freezing in liquid nitrogen for $5 \mathrm{~min} \&$ immediately transferred into water bath $95^{\circ} \mathrm{C}$ for $5 \mathrm{~min}$. repeated for 5 cycles) the obtained DNA was measured for concentration and purity.

Copro n-PCR / RFLP analyses: CopronPCR was done targeting COWP gene. PCR amplification was performed in a $25 \mu 1$ volume containing $12.5 \mu 1$ master mix, $200 \mathrm{n} M$ from each primer, and $3 \mu 1$ of the template DNA for the primary reaction and $1 \mu 1$ for the secondary one. The cycling conditions were 35 cycles at $94^{\circ} \mathrm{C}$ for $1 \mathrm{~min},\left(63^{\circ} \mathrm{C}\right.$ for $1 \mathrm{~min}$ for $1 \mathrm{ry} \& 54^{\circ} \mathrm{C}$ for $30 \mathrm{~s}$ for nested 54) and $72^{\circ} \mathrm{C}$ for $1 \mathrm{~min}$, followed by $10 \mathrm{~min}$ at $72^{\circ} \mathrm{C}$. The amplified products were visualized with $1.5 \%$ agarose gel electrophoresis after ethidium bromide staining. Amplified products of nPCR of positive sample of COWP gene were digested using Rsa I endonuclease after manufacture instruction and resolved using 3\% Metaphor electrophoresis after ethidium bromide staining.

Enzymatic amplification and HRM curve analysis: The ITS-2 region (440-450 bp) was PCR-amplified from genomic DNA samples using primers AP58SF (forward: 5'-ATC TCT CAA GCG AAA TAG CAG TAA-3') and APITS-2R (reverse: 5'-CCC ATT GAT AAA CGG ATT TCC-3') (Pangasa et al, 2009). PCR was performed in $25 \mathrm{ml}$ volumes containing $200 \mathrm{nM}$ of each primer, $12.5 \mu \mathrm{l}$ of Luminaris color HRM master mix (Thermo scientific), $4.5 \mu 1$ nuclease-free water and 3 $\mu \mathrm{l}$ of the template DNA using the thermo cycling conditions (Pangasa et al, 2009). In every run, positive and negative controls were included, and the cycle threshold and melting-curve values were recorded. 
Statistical analysis: Data were coded and entered using the statistical package SPSS version 17 (Chicago, IL, USA) for statistical analysis.

\section{Results}

Demographic, clinical and initial laboratory data of study samples: Cases presented variable GIT symptoms were assessed medically. The mean age of subjects under study was 4.59 years \pm 3.38 standard deviation (SD), $56.1 \%$ of them were males and $43.9 \%$ were females with male/female ratio 1:3. Total of $326(97.3 \%)$ children used tap water and $81(24.2 \%)$ had a history of animal contact. Main symptom of all was diarrhea in 141(42.1\%) cases.

Occurrence and Genotyping of Cryptosporidium: Out of 335 examined stool sam- ples with AF stain (Figure 1), Cryptosporidium oocysts were found in 12 samples (3.6\%). Further assessment by nPCR targeting COWP gene revealed positivity in 43 (12.8\%) stool samples (Figs. 2 \& 3 ).

The specific categorization of samples using PCR-coupled HRM identified 38 cases for which $C$. hominis presented two peaks (profile 1), and 5 cases were $C$. parvum with one peak (profile 2) (Tab.1; Fig. 4).

Cryptosporidium genotypes and risk factors: The study showed no significant correlation between Cryptosporidium species and demographic and clinical variants. However, there was a positive correlation between Cryptosporidium species and with symptomatic patient $(P<0.05)$.

Table 1: Used primers and their sequences.

\begin{tabular}{|l|l|l|l|l|l|}
\hline \multicolumn{2}{|c|}{} & Primers & Sequence & Expected product size (bp) & Reference \\
\hline \multirow{2}{*}{$\begin{array}{l}\text { COWP } \\
\text { gene }\end{array}$} & 1ry & BCOWPF & 5'ACCGCTTCTCAACAACCATCTTGTCCTC-3' & & (Pedraza-Díaz \\
\cline { 2 - 4 } & PCR & BCOWR & 5'-CGCACCTGTTCCCACTCAATGTAAACCC-3' & 769-bp & \\
\cline { 2 - 4 } & nPC & Cry-15 & 5-GTAGATAATGGAAGAGATTGTG-3 & 553-bp \\
\cline { 2 - 4 } & R & Cry-9 & 5-GGACTGAAATACAGGCATTATCTTG-3 & & \\
\hline
\end{tabular}

Table 2: Number of samples and the profile of PCR-coupled melting-curve analysis targeting ITS-2 amplicons.

\begin{tabular}{|l|l|l|l|}
\hline & N. of samples & Peak 1 & Peak 2 \\
\hline Profile I (C. hominis) & 38 & $72.7^{0} \mathrm{C}$ & $74.9^{0} \mathrm{C}$ \\
\hline Profile II (C. parvum) & 5 & $77.8^{0} \mathrm{C}$ & - \\
\hline
\end{tabular}

\section{Discussion}

In the last decades in Egypt, there has been a reported varying Cryptosporidium preva-lence, a high of molecular prevalence rate of infection was shown in many studies up to $25 \%$ of the examined patients (ElSettawy and Fathy, 2012; Fathy et al, 2014; Ghallab et al, 2014). In contrast, much lower results (4.6\%) reported (Abd ElKader et al, 2011). The diminished sensitivity of AF stain in the study might be due to the high threshold ne-cessary for oocyst detection in watery stool where the detection rate could be accom-plished at a concentration of 10,000 oocysts/ g stool (Weber et al, 1991).

Genotypic discrimination, PCR-RFLP analysis yielded $C$. hominis predominance in 38 samples $(88.4 \%)$ and $C$. parvum in 5 cases $(11.6 \%)$. Mixed infection wasn't detected, indicating that the main source of Cryptosporidium infection was anthroponotic ra- ther than zoonotic. These findings agreed with two Egyptian studies (Abdel-Kader et al, 2011; Ibrahim et al, 2016) and differred from two studies (Eida et al, 2009; Sadek, 2014). In industrialized nations, C. hominis predominates among human cryptosporidiosis, as in Spain (65.7\%), USA (67\%), Japan (68\%), Australia and Canada (76\%). As well as, in developing countries, as Peru (79\%), South Africa (82\%) and Thailand $(83 \%)$, indicating that anthroponotic species were the main cause of human infection. The re-lation of $C$. parvum/C. hominis was however more balanced in other countries, as England and Wales (49.2\%), France $(51 \%)$ and Bel-gium (54.2\%), while $C$. parvum dominated in the Netherlands $(72 \%)$ and Italy (90\%) (Ong et al, 2002; Samie et $a l$, 2006; Liorente et al, 2007; Geurden et al, 2009).

PCR coupled HRM curve analysis targeting ITS-2 gene confirmed the results of 
copro-nPCR/RFLP. PCR coupled HRM curve achieve parasite specific identification and differentiation (Monis et al, 2005). The presence of multiple peaks in HRM is diagnostically informative, giving a unique profile with an increased number of characters for the resolution of species and/or genotypes (Robinson et al, 2006). PCRcoupled HRM-curve analysis is suited for the quick screening of many Cryptosporidium oocyst DNA samples as there was no requirement for the handling, pouring, and/ or scanning of electrophoretic gels, thus con-siderably diminishing overall time and cost. It is a closed-tube genotyping method that eliminates risk of contamination. The qualit- a tive approach, exhibited certain advantages over other electrophoretic ones (Gasser et al, 2001), mainly in relation to sample through-put, analysis time, analysis capacities and data storage. Risk of carryover contamina-a tion and materials' cost were much lower than that for others (Zhang et al, 2012).

HRM master mix used in this study contained a third-generation florescent dye (Eva green). This dye proved ideal with good stability and instrument compatibility coupled with optimal DNA-binding characteristics, including low or no affinity for ssDNA, and short DNA fragments and a just-right affinity for dsDNA, thus increasing the specificity of HRM reaction (Mao et al, 2007).

In the present study, only children with diarrhea and other GIT symptoms showed significant cryptosporidiosis association. In contrast, El-Helaly et al. (2012) and Jiang et al. (2014) reported a higher infection rate in males than females, Park et al. (2006) found a significant correlation between cryptosporidiosis and sexes, as boys were more susceptible than girls to infection. Untreated water, animal contact and farm visit have been reported as risk factors for infection in many studies. Others did not find relationship between infection and drinking water or animal contact (Khalili and Mardani, 2009).

GIT symptoms including diarrhea, abdominal pain, flatulence, itching, vomiting, or ap- petite loss (Chauret et al, 1999) are known risk factors for cryptosporidiosis.

Clinical manifestations in cryptosporidiosis might be correlated to different species and subtypes. Cama et al. (2008) reported that cases with $C$. parvum, C. felis, C. canis, and $C$. meleagridis infection were associated with diarrhea only, but diarrhea, nausea, vomiting, and general malaise were associated with cryptosporidiosis. Mumtaz et al. (2010) reported that environmental, clinical and host behavioral factors acted as important risk factors for infection but neither affecting the pathogenicity nor the disease course. In the present study, the high population densities with greater chance of person-to-person transmission and variation in socioeconomic population status within same geographical areas might play an important role in the differences reported in the prevalence of the disease and may explain the obtained results in the present study.

\section{Conclusion}

There is $C$. hominis predominance among Egyptian children. HRM curve analysis, a closed-tube genotyping method, confirmed the results of copro-nPCR/RFLP. It is simple, without probe, rapid, has more sample throughput, analysis capacities and data storage with less carry-over contamination and cost.

Contribution of each author: All manuscript authors contributed to every activity: idea of paper, study design, collection of materials, methodology, writing and revising the paper.

Conflict of Interest: The authors declared that they neither have competing interests nor received fund.

\section{References}

Abd El-Kader, MN, Blanco, M, Tammam, M A, Abd El Ghaffar, AB, Osman, A, et al, 2011: Detection of Cryptosporidium parvum and Cryptosporidium hominis in human patients in Cairo, Egypt. Parasitol. Res. 110, 1:2465-70.

Cama, VA, Bern, C, Roberts, J, Cabrera, L, Sterling, CR, et al, 2008: Cryptosporidium species and subtypes and clinical manifestation in children, Peru. Emerg. Infect. Dis. 14, 10: 1567-74.

Chauret, C, Springthorpe, S, Sattar, S, 1999: 
Fate of Cryptosporidium oocysts, Giardia cysts, and microbial indicators during waste water treatment and anaerobic sludge digestion. Can. J. Microbiol. 45, 3:257-62.

Eida, AM, Eida, MM, El-Desoky, A, 2009: Pa-thological studies of different genotypes of human Cryptosporidium Egyptian isolates in experimentally mice. J. Egypt Soc. Parasitol. 39, 3: 975-90.

El-Helaly, NS, Aly, MA, Attia, SS 2012: Detection of Cryptosporidium Infection among children with diarrhea. New York Sci. J. 5, 7:68-76.

El-Settawy, MA, Fathy, GM, 2012: Evaluation and comparison of PCR, coproantigen ELISA and microscopy for diagnosis of Cryptospori dium in human diarrheic specimens. J. Am. Sci. 8, 12:1385-78.

Elwin, K, Hadfield, SJ, Robinson, G, Crouch, ND, Chalmers, RM, 2012: Cryptosporidium viatorum sp. among travellers returning to Great Britain from the Indian subcontinent, 20072011. Int. J. Parasitol. 42:675-82.

Fathy, MM, Abdelrazik, NM, Hassan, FA, El-Badry, AA, 2014: Molecular copro-prevalence of Cryptosporidium in Egyptian Children and evaluation of three diagnostic methods. Res. Brief. 51:727-9.

Fayer, R, Santín, M, Macarisin, D, 2010: Cryptosporidium ubiquitum sp. in animals and humans. Vet. Parasitol. 172:23-32.

Garcia, LS, 2007: Diagnostic Medical Parasitology, $5^{\text {th }}$ ed. ASM Press, Washington D. C.

Gasser, RB, Zhu, XQ, Caccio,'S, Chalmers, R, Widmer, G, et al, 2001: Genotyping Cryptosporidium parvum by single-strand conformation polymorphism analysis of ribosomal and heat shock gene regions. Electroph. 22, 3:433-7.

Geurden, T, Levecke, B, Cacció, SM, Visser, A, De Groote, G, et al, 2009: Multilocus genotyping of Cryptosporidium and Giardia in non-outbreak related cases of diarrhea in human patients in Belgium. Parasitol. 136, 10:1161-8.

Ghallab, MMI, Abdel Aziz, IZ, Shoeib, EY, El-Badry, AA, 2014: Laboratory utility of coOproscopy,copro-immunoassays \& copro-nPCR assay targeting Hsp90 gene for detection of Cryptosporidium in children, Cairo, Egypt. J.

Parasit. Dis. 40:901-5.

Ibrahim, MA, Abdel-Ghany, AE, AbdelLatef, GK, Abdel-Aziz, S, Aboelhadid, S, 2016: Epidemiology and public health significance of Cryptosporidium isolated from cattle, buffaloes, and humans in Egypt. Parasitol. Res. 115, 6:2439-48
Jiang, Y, Ren, Y, Yuan, Z, Liu, A, Zhao, H, et al, 2014: Cryptosporidium andersoni as a novel predominant Cryptosporidium species in outpatients with diarrhea in Jiangsu Province, China. B.M.C. Infect. Dis. 14:1-6.

Jothikumar, N, da Silva, AJ, Moura, I, Qvarnstrom, Y, Hill, VR, 2008: Detection and differentiation of Cryptosporidium hominis and Cryptosporidium parvum by dual TaqMan assays. J. Med. Microbiol. 57, 9:1099-105.

Khalili, B, Mardani, M, 2009: Frequency of Cryptosporidium and risk factors related to cryptosporidiosis in under 5-year old hospitalized children due to diarrhea. Iranian J. Clin. Infect. Dis. 4, 3:151-5.

Kotloff, KL, Nataro, JP, Blackwelder, WC, et al, 2013: Burden and etiology of diarrhoeal disease in infants and young children in developing countries (the Global Enteric Multicenter Study, GEMS): a prospective, casecontrol study. Lancet 382, 9888:209-22.

Liorente, MT, Clavel, A, Goñi, MP, Varea, M, Seral, C, et al, 2007: Genetic characterization of Cryptosporidium species from humans in Spain. Parasitol. Int. 56, 3:201-5.

Mao, F, Leung, WY, Xin, X, 2007: Characterization of EvaGreen and the implication of its physicochemical properties for qPCR applications. B.M.C. Biotechnol. 7:76-9.

Monis, PT, Giglio, S, Saint, PC, 2005: Comparison of SYTO9 and SYBR Green I for realtime polymerase chain reaction and investigation of the effect of dye concentration on amplification and DNA melting curve analysis. Anal. Biochem. 340:24-34.

Montgomery, J, Wittwer, CT, Palais, R, Zhou, L, 2007: Simultaneous mutation scanning and genotyping by high resolution DNA melting analysis. Nat. Protoc. 2:59-66.

Mumtaz, S, Ahmed, J, Ali, L, 2010: Frequency of Cryptosporidium infection in children under five years of age having diarrhea in the North west of Pakistan. Afr. J. Biotechnol. 9, 8:12305 .

Ong, CS, Eisler, DL, Alikhani, A, Fung, VW, Tomblin, J, et al, 2002: Novel Cryptosporidium genotypes in sporadic cryptosporidiosis cases: first report of human infections with a cervine genotype. Emerg. Infect. Dis. 8, 3:263-8.

Pangasa, A, Jex, AR, Campbell, BE, Bott, NJ, Whipp, M, et al, 2009: High resolution melting-curve (HRM) analysis for the diagnosis of cryptosporidiosis in humans. Mol. Cell Probes 23, 1: 10-5. Park, JH, Kim, HJ, Guk, SM, Shin, EH, Kim, JL, et al, 2006: A survey 
of cryptosporidiosis among 2,541 residents of 25 coastal islands in Jeollanam-Do (Province), Republic of Korea. K.

J. Parasitol. 44, 4:367-72.

Robinson, BS, Monis, PT, Dobson, PJ, 2006: Rapid, sensitive and discriminating identification of Naegleria spp. by real-time PCR and melting-curve analysis. Appl. Environ. Microbiol. 72:5857-63.

Sadek, GM, 2014: Use of nested PCR-RFLP for genotyping of Cryptosporidium parasites iso-lated from calves and children suffering from di-arrhea. J. E.P.U. 7, 2:129-37.

Samie, A, Bessong, PO, Obi, CL, Sevilleja, J
E, Stroup, S, et al, 2006: Cryptosporidium species: preliminary descriptions of the prevalence and genotype distribution among school children and hospital patients in the Venda region, Limpopo Province, South Africa. Exp. Parasitol. 114, 4:314-22.

Weber, R, Bryan, R, Juranek, D, 1991: Improved stool concentration procedures for detection of Cryptosporidium oocysts in in fecal specimens. J. Clin. Microbiol. 30, 11:2869-73.

Zhang, P, Liu, Y, Alsarakibi, M, Li, J, Liu, T, et al, 2012: Application of HRM assays with EvaGreen dye for genotyping Giardia duodenalis zoonotic assemblages. Parasitol. Res. 111: 2157-63

\section{Explanation of figures}

Fig. 1: Cryptosporidium oocysts stained with cold Kinyoun's AF stain.

Fig.2: Agarose gel electrophoresis for products of nPCR targeting COWP gene of Cryptosporidium at 533 bp., Lane 1: 100 bp DNA molecular weight marker, Lane 2: Positive control, Lanes 3: Negative control \&Lanes 4- 6: Positive samples.

Fig. 3: Agarose gel electrophoresis for COWP RFLP products after digestion with RsaI endonuclease. Lane 1: 100 bp DNA marker ladder, Lanes 2\&3: C. hominis genotype I digestion products at 34, 106, and 410 bp using RsaI \& Lane 4\&5: C. parvum gentype II digestion products at $34,106,125$ and $285 \mathrm{bp}$.

Fig. 4: Representative profiles in melting-curve analysis of ITS-2 amplicons for C. hominis (red) (A), C. parvum (black) (B).
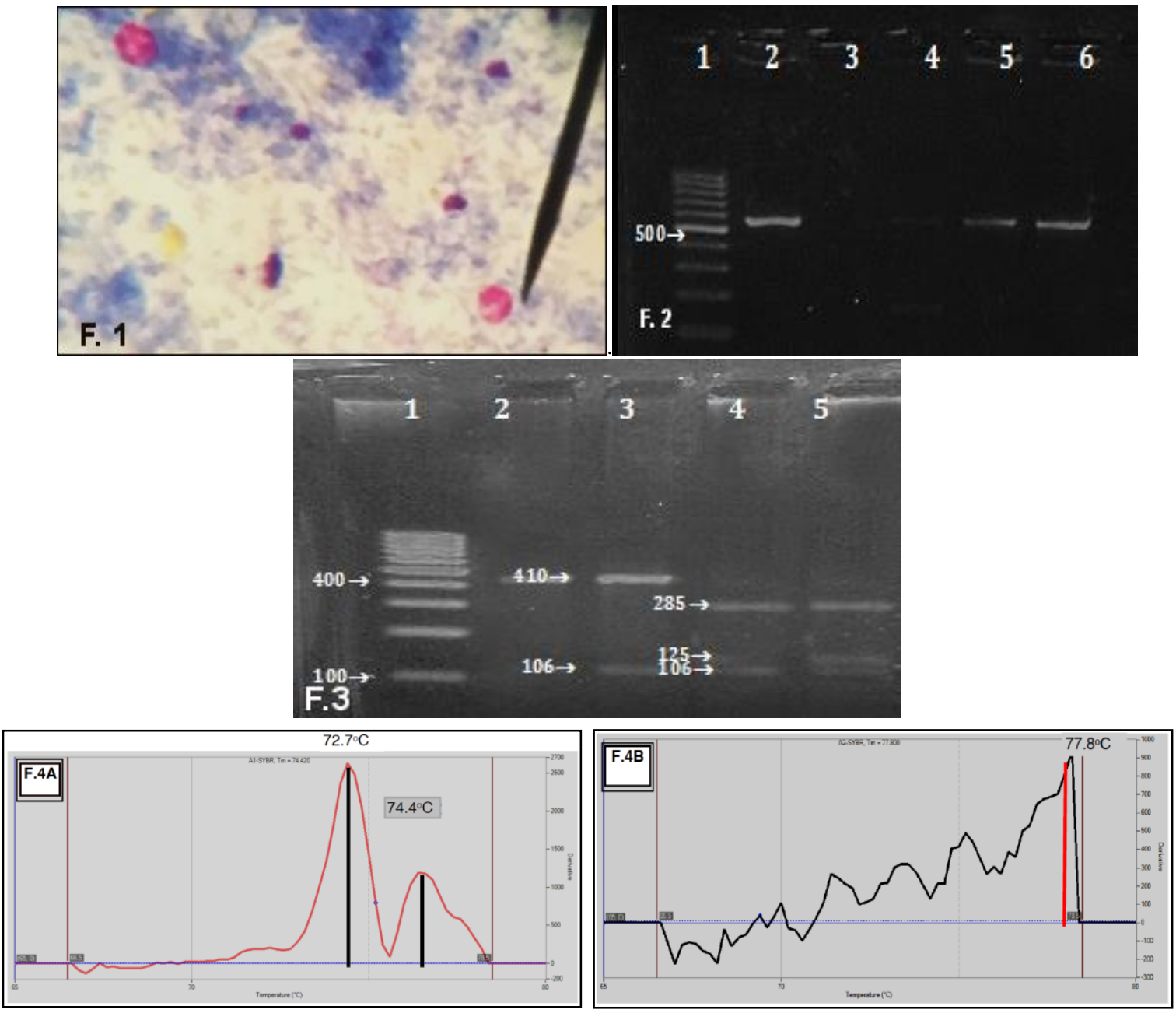